\title{
SOROPREVALÊNCIA DA DOENÇA CELÍACA EM AMBULATÓRIO PEDIÁTRICO, NO NORDESTE DO BRASIL
}

\author{
Kátia Galeão BRANDT e Giselia Alves Pontes da SILVA
}

\begin{abstract}
RESUMO - Racional - A doença celíaca é uma enfermidade freqüente que afeta crianças e adultos e cujo diagnóstico e tratamento precoces previnem complicações e mortes. Ainda são escassos os estudos de soroprevalência em nosso meio. Objetivos - Conhecer a soroprevalência da doença celíaca, utilizando-se os anticorpos anti-endomísio e antitransglutaminase tecidual humana, em crianças e adolescentes atendidos em um ambulatório de pediatria geral. Métodos - O desenho foi descritivo do tipo corte transversal, um estudo de soroprevalência. Inicialmente foram dosados os anticorpos antitransglutaminase tecidual guinea pig e posteriormente nos positivos, dosados os anticorpos anti-endomísio e antitransglutaminase tecidual humana. Resultados - A soroprevalência para doença celíaca através do anticorpo antitransglutaminase tecidual guinea pig foi de 5\% (42/831; IC de 95\%: 3,76\%-6,90\%), considerando os três testes positivos a soroprevalência foi de 1,9\% (16/831; IC de 95\%: 1,83\%-1.97\%). A concordância do TTGhumana com o anticorpos anti-endomísio foi de $71 \%$. Conclusões - A soroprevalência de doença celíaca foi elevada. A triagem sorológica em crianças e adolescentes que apresentem sinais e/ou sintomas compatíveis deve ser realizada rotineiramente, bem como nos grupos de risco já conhecidos, dada a sua alta soroprevalência observada em nosso meio.
\end{abstract}

DESCRITORES - Doença celíaca. Estudos soroepidemiológicos. Pacientes ambulatoriais. Criança. Adolescente.

\section{INTRODUÇÃO}

A doença celíaca (DC) é uma enfermidade freqüente que afeta crianças e adultos e cujo diagnóstico e tratamento precoces previnem complicações e mortes ${ }^{(25)}$. Estudos realizados, principalmente na Europa e nos Estados Unidos, indicam que a DC ocorre em torno de $0,5 \%$ a $1 \%$ da população geral ${ }^{(5,6)}$.

Os testes sorológicos permitem rastrear de forma menos invasiva maior número de pessoas, assegurando que formas clínicas leves, com sintomas não-característicos, ou mesmo indivíduos assintomáticos sejam identificados ${ }^{(14,18)}$.

$\mathrm{O}$ anticorpo antigliadina (AGA) avalia a presença de anticorpos de classe IgA e IgG contra a fração tóxica do trigo (a gliadina), geralmente medidos através da técnica de ELISA ${ }^{(1)}$. Foi largamente utilizado até pouco tempo, mas teve seu uso desaconselhado em revisões recentes $^{(14,15)}$.

O anticorpo anti-endomísio (EMA) avalia a presença de anticorpos da classe IgA dirigidos contra o endomísio. Apesar de ser um teste sensível e específico, o EMA apresenta algumas dificuldades para seu uso em grande escala: custo elevado, técnica laboriosa e necessidade de sacrificar animais (quando utilizado esôfago de macaco). Além do mais, por ser um método semiquantitativo, está sujeito, em parte, à avaliação do observador ${ }^{(8,15)}$.

A pesquisa do anticorpo antitransglutaminase tecidual (TTG) é útil na investigação sorológica para DC por ser realizada através da técnica de ELISA, sendo portanto, de mais fácil execução, fornecendo resultado quantitativo e não dependente de operador e, ainda, por apresentar sensibilidade e especificidade que se assemelham ao EMA $^{(4,15)}$.

Ainda hoje, são poucos os estudos de prevalência da DC na América do Sul. A maioria dos trabalhos foi realizada na Europa, onde as condições sociais e ambientais são muito diferentes ${ }^{(5)}$.

Em 2000, foram publicados os primeiros estudos sobre prevalência da DC na América do Sul, tendo o primeiro sido realizado no Brasil ${ }^{(10,12)}$. Em 2006, MELO et al. ${ }^{(20)}$ observaram entre doadores de sangue, em Ribeirão Preto, prevalência estimada de DC de 1:273. Recentemente, OLIVEIRA et al. ${ }^{(23)}$ encontraram em população semelhante, prevalência de 1:214 na cidade de São Paulo.

A DC ainda é vista por leigos e alguns médicos como rara. A realização de estudos de soroprevalência contribui tanto para um melhor conhecimento do seu impacto em nosso meio, quanto para a seleção dos indivíduos que precisam ser submetidos a biopsia do intestino delgado, imprescindível para a confirmação da doença ${ }^{(25)}$.

O objetivo deste estudo foi conhecer a soroprevalência da DC, utilizando-se testes sorológicos para EMA e TTG em crianças e adolescentes atendidos em um ambulatório de pediatria geral.

Programa de Pós-Graduação em Saúde da Criança e do Adolescente, Universidade Federal de Pernambuco, Recife, PE.

Correspondência: Dra. Giselia Alves Pontes da Silva - Rua Simão Mendes, 195/202 - 52050-110 - Recife, PE. E-mail: giselia.alves@pq.cnpq.br 


\section{MÉTODOS}

O estudo foi realizado no Instituto Materno-Infantil Professor Fernando Figueira - IMIP, entidade de direito privado, sem fins lucrativos, conveniado com o Sistema Único de Saúde (SUS) e credenciado pelo Ministério da Saúde como Centro de Referência Nacional para a assistência na área materno-infantil, localizado em Recife, PE.

O desenho do estudo foi descritivo do tipo corte transversal, realizando-se estudo de soroprevalência, através da dosagem dos anticorpos antitransglutaminase tecidual guinea pig (TTGgp) e nos positivos dosados os anticorpos antitransglutaminase tecidual humana (TTGh) e EMA. A população do estudo foi formada por crianças maiores de 2 anos e adolescentes, atendidos nos vários setores da instituição, que realizaram coleta sangüínea no laboratório, durante o período do estudo, independente da indicação clínica.

O tamanho da amostra foi calculado utilizando-se o programa "statcalc" do EPI-INFO 6.0. Para o cálculo utilizouse a soroprevalência (4\%) obtida com os 100 primeiros soros analisados; com nível de confiança de $95 \%$, foi obtido um $n=637$. Foi analisado número maior de crianças para dar maior consistência aos resultados. Os indivíduos foram selecionados de forma não aleatória, por critério de conveniência, segundo a demanda do próprio laboratório.

Foram excluídos os familiares de pacientes celíacos já conhecidos, os doentes com diabetes tipo I e os com síndrome de Down (indivíduos sabidamente com risco maior para DC que a população geral).

O sangue coletado era colocado em tubo seco e submetido a centrifugação para obtenção do soro, sendo armazenado em condições adequadas de temperatura. A sorologia para TTGgp foi realizada no laboratório do IMIP e supervisionada por profissional de nível superior, treinada em exames sorológicos para DC, pertencente à Universidade de Trieste, Itália. A sorologia para EMA e a TTGh foi realizada no laboratório da Universidade de Trieste pela mesma profissional.

Inicialmente, foram utilizados os kits de TTGgp produzidos pelo laboratório Eurospital, de Trieste, Itália. Foi avaliada a presença de anticorpos da classe IgA. A concentração de anticorpos foi expressa em unidades arbitrárias (UA) e considerado positivo os valores acima de 7,0 UA (valor previamente estabelecido pelo laboratório).

Nos indivíduos com sorologia para TTGgp positiva foram realizadas provas sorológicas com EMA e TTGh. O EMA sérico foi medido através da técnica de imunofluorescência indireta, utilizando secções criostáticas de tecido de cordão umbilical humano. Uma fluorescência, tipo "favo de mel", ao longo das camadas musculares peritubulares do cordão umbilical humano foi considerada positiva para EMA.

OTTGh foi avaliado através da técnica de ELISA, utilizandose como substrato enzima clonada pelo grupo de Trieste. Os resultados foram expressos como percentual do soro positivo controle, sendo considerados normais valores abaixo de $16 \%$ do soro positivo controle, que representou um valor $>2 \mathrm{DP}$ acima da média de 100 indivíduos saudáveis.
A pesquisa teve início após aprovação pela Comissão de Ética em Pesquisa do IMIP e do Comitê de Ética em Pesquisa do Centro de Ciências da Saúde da Universidade Federal de Pernambuco.

Os dados foram armazenados em arquivo do Epi-Info 6.0, sendo utilizados os programas Check e o Validate para assegurar a consistência dos dados.

As variáveis categóricas que caracterizam a amostra, foram expressas em percentuais. A prevalência foi calculada através da proporção dos indivíduos com sorologia positiva em relação à amostra estudada. A concordância sorológica foi determinada pelo somatório das sorologias positivas e negativas que concordaram para EMA e TTGh, sobre o número total de sorologias realizadas para os dois testes.

\section{RESULTADOS}

No período de março a agosto de 2000 , realizou-se a sorologia em 831 crianças e adolescentes. A amostra constituiu-se de 52\% (433/831) de indivíduos do sexo feminino e 48\% (398/831) do masculino.

A idade das crianças e dos adolescentes variou entre 2 a 18 anos, com mediana de 8 anos. A distribuição de freqüência por grupo etário foi: pré-escolares $29 \%$ (241/831), escolares $27 \%$ (225/831) e adolescentes 44\% (365/831).

A soroprevalência para DC obtida através do anticorpo TTGgp, foi de 5\% (42/831; IC de 95\%: 3,76\%-6,90\%). Considerando os indíviduos que tiveram os três testes positivos, a soroprevalência estimada foi de 1,9\% (16/831; IC de 95\%: $1,83 \%-1,97 \%)$.

A concordância do TTGh com o EMA foi de $71 \%, 16$ TTG h e EMA positivos somados a 14 TTGh e EMA negativos, total de 30 sorologias concordantes (Figura 1). Em todos os indivíduo EMA positivo, o TTGh foi positivo.

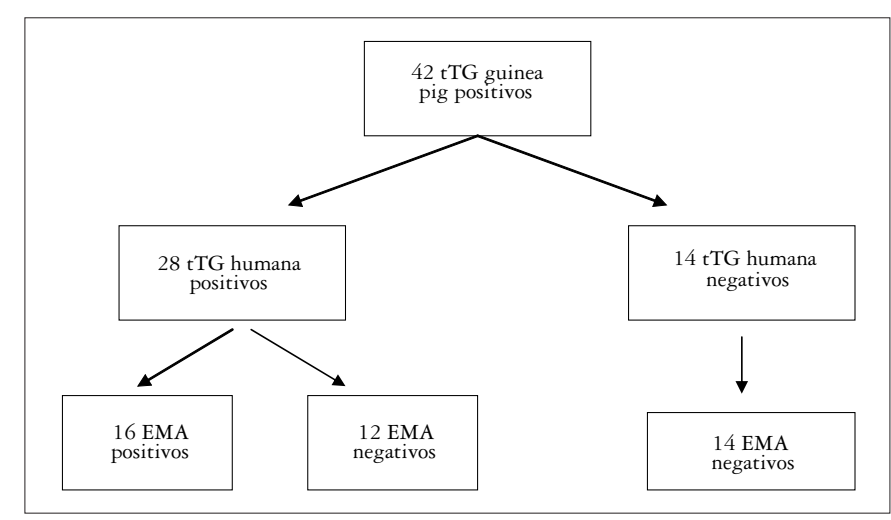

FIGURA 1. Concordância sorológica: tTG guinea pig, tTG humana e EMA

\section{DISCUSSÃO}

Os estudos de rastreamento populacional, que se tornaram possíveis com o advento dos testes sorológicos, mostram uma soroprevalência da DC na população geral bastante significativa $a^{(5,6,11,15)}$. 
Neste trabalho, a soroprevalência estimada, utilizando-se o anticorpo anti-TTGgp como um exame de triagem inicial e os positivos confirmados com o TTGh e o EMA, foi de $1,9 \%$ (16/831; IC de 95\%: 1,83\%-1.97\%). A soroprevalência média da DC encontrada através dos programas de rastreamento populacional realizados, principalmente na Europa, situa-se em torno de $1 \%{ }^{(14)}$. Sabe-se que para a confirmação da doença é necessária a realização da biopsia intestinal, pois o indivíduo pode apresentar anticorpos mas não preencher os critérios que definem a presença da doença ${ }^{(15)}$. Daí o cuidado de se observar nos diferentes estudos se a proposta foi conhecer a soroprevalência ou a prevalência da DC.

Um aspecto que diferencia esta população da de outros estudos é o fato de tratar-se de uma amostra colhida em ambiente hospitalar, o que poderia justificar a existência de maior número de indivíduos com sorologia positiva, já que é de se esperar que em uma população de indivíduos "doentes" exista maior número de celíacos. Vale salientar que em estudo semelhante, realizado em Oxford, na Inglaterra ${ }^{(16)}$, foi encontrado grande número de celíacos entre pacientes que vinham sendo acompanhados em ambiente hospitalar (prevalência de $3 \%$ ) e que, até o momento do rastreamento sorológico, não haviam sido diagnosticados. Os autores alertam para o subdiagnóstico da DC mesmo em ambiente hospitalar.

Apesar do exposto, em estudo realizado anteriormente no Brasil por GANDOLFI et al. ${ }^{(9)}$, no qual foi investigada a prevalência de DC em 1.686 crianças acompanhadas no ambulatório do Hospital Universitário de Brasília, encontrouse uma soroprevalência bastante inferior. As crianças foram rastreadas através de EMA, tendo sido identificados seis indivíduos positivos; destes, cinco concordaram com a realização da biopsia do intestino delgado, que demonstrou um padrão celíaco. A prevalência da DC foi de 1:281, ou seja, $0,35 \%$. O critério utilizado para a triagem, através da dosagem dos EMA, explica em parte o menor percentual de soropositividade.

Certamente, estudos de soroprevalência e o refinamento diagnóstico através da realização de biopsia intestinal, irão ajudar a estabelecer a verdadeira prevalência da DC em diferentes regiões e populações no Brasil. Fatores relacionados ao ambiente, como diferentes práticas alimentares e fatores agressores do meio ambiente, podem explicar as diferenças na prevalência de DC em nosso país quando comparadas aos estudos europeus ${ }^{(13)}$.

Enquanto se sabe que a ingestão de glúten é responsável pelo desenvolvimento dos sinais e dos sintomas da DC, não se conhece quais fatores estariam associados ao desenvolvimento ou não da doença e a época de início da mesma. Estudos epidemiológicos anteriores já constataram que diferentes práticas alimentares, principalmente no que se refere à época de introdução do glúten e sua quantidade na dieta, podem influenciar a prevalência da DC em uma população ${ }^{(13,19)}$.

NORRIS et al. ${ }^{(22)}$ acompanharam prospectivamente 1.560 crianças com risco maior de desenvolver DC, por possuírem seu marcador genético ou por serem familiares de primeiro grau de doentes com diabetes mellitus tipo I, condição fortemente associada à DC. Essas crianças foram acompanhadas por 5 anos, período em que os autores tentaram observar a associação entre a época de introdução do glúten com o risco de desenvolver DC, constatando que a introdução de glúten nos primeiros 3 meses de vida esteve associada a um risco 5 vezes maior da criança desenvolver DC, em relação às crianças que iniciaram sua ingestão entre 4 e 6 meses de vida. Crianças que não ingeriram glúten até 7 meses ou mais, também apresentaram risco marginalmente aumentado. Os autores concluíram que a época de introdução do glúten na dieta das crianças está associada com o desenvolvimento ou não de doença.

É provável que na população deste estudo, considerada socioeconomicamente carente, o trigo (na forma de massas, pães, biscoitos, macarrão), principal fonte de glúten, seja introduzido precoce e abundantemente, por tratar-se de alimento de baixo custo e do gosto popular. Por outro lado, sabe-se que, ao contrário do que deveria ocorrer, a maioria das crianças é desmamada precocemente, antes dos 6 meses. Não se pode afastar a possibilidade do hábito alimentar estar associado à alta soroprevalência observada. A presença de fatores agressores do meio ambiente contribuindo para a ocorrência da DC tem sido pouco estudada. Diante do que se conhece atualmente sobre a patogênese da DC, acredita-se ser necessário um fator que altere a barreira do trato digestório, promovendo maior influxo de gliadina e liberação de TTG, para que se desenvolva a $\mathrm{DC}^{(2,17)}$. É razoável especular que fatores como desnutrição, infecções intestinais de repetição e parasitoses intestinais favoreceriam ambiente apropriado para o desencadeamento da doença.

A busca por um teste sorológico preciso para o diagnóstico de DC é um dos maiores desafios na atualidade. A necessidade de biopsia de intestino delgado para confirmar o diagnóstico de DC torna a investigação invasiva e requer profissional médico treinado para a realização do procedimento. Teste diagnóstico que não seja invasivo e que esteja prontamente disponível seria o ideal, não só para conveniência do paciente, mas também para otimizar o uso dos recursos em saúde ${ }^{(7,21,24)}$.

Observou-se, nos pacientes que realizaram os três testes, que a concordância da TTGgp, principalmente com o EMA, não foi satisfatória (apenas 34\%); tais achados fazem levantar questionamentos sobre o kit sorológico utilizado na triagem inicial.

O grupo de trabalho em rastreamento sorológico para DC da Alemanha, em publicação de novembro de 2000, relata serem muitos os métodos descritos para determinação de seus anticorpos e que a padronização de métodos e materiais é de suma importância, já que avaliações interlaboratoriais prévias têm demonstrado resultados conflitantes ${ }^{(26)}$. Nesse estudo, houve a participação de sete diferentes laboratórios europeus, a análise sorológica utilizando o TTGgp apresentou reprodutibilidade interlaboratorial que não alcançou o EMA. Surgiram questionamentos sobre variações nos protocolos dos testes e a respeito dos preparados de TTGgp utilizados como antígeno, tendo sido observada diferenças na dependência do lote da enzima empregada.

No trabalho realizado por CLEMENTE et al. ${ }^{(3)}$ intitulado "Armadilhas no rastreamento para DC utilizando transglutaminase 
guinea pig ELISA", relatou-se alta freqüência de resultados falso-positivos $(50 \%)$ em indivíduos com outras doenças auto-imunes, particularmente hepatite auto-imune e cirrose biliar primária.

Em vista da elevada soroprevalência observada no presente estudo, especula-se como possível explicação para este achado a existência de fatores ambientais que, atuando numa fase precoce da vida das crianças, levem a aumento da permeabilidade intestinal, facilitando a sensibilização ao glúten e, conseqüentemente, o desencadeamento da DC.
Conclui-se que a triagem sorológica para DC em crianças e adolescentes que apresentem sinais e/ou sintomas compatíveis com a mesma deve ser realizada em todos os níveis de atendimento, bem como nos grupos de risco já conhecidos, dada a soroprevalência observada em nosso meio.

\section{AGRADECIMENTOS}

As autoras são gratas a Chiara Trevisiol, Sérgio Crovella e Alessandro Ventura pela viabilização dos exames laboratoriais.

Brandt KG, Silva GAP. Seroprevalence of celiac disease at a general pediatric outpatient clinic. Arq Gastroenterol. 2008;45(3):239-42.

ABSTRACT - Background - Celiac disease is a common problem affecting children and adults, for which early diagnosis and treatment prevent complications and deaths. Seroprevalence studies in our environment are still scarce. Aims - To determine the seroprevalence of celiac disease by using human tissue antiendomysial and anti-transglutaminase antibodies, among children and adolescents who were attended at a general pediatric outpatient clinic. Methods - This was a seroprevalence study of descriptive cross-sectional design. First, assays for guinea pig tissue anti-transglutaminase antibodies were performed. Subsequently, in the positive cases, assays for human tissue antiendomysial and anti-transglutaminase antibodies were performed. Results - The seroprevalence of celiac disease by means of anti-guinea pig tissue anti-transglutaminase antibodies was 5\% (42/831; $95 \%$ CI: 3.76\%-6.90\%). Considering three positive tests, the seroprevalence was $1.9 \%$ (16/831; $95 \%$ CI: $1.83 \%-1.97 \%)$. The concordance of human anti-transglutaminase with antiendomysial was $71 \%$. Conclusions - The seroprevalence of celiac disease was high. Serological screening for celiac disease among children and adolescents who present signs and/ or symptoms compatible with celiac disease should be performed routinely, as well as in groups already known to be at risk, given the high seroprevalence of celiac disease observed in our environment.

HEADINGS - Celiac disease. Seroepidemiologic studies. Outpatients. Child. Adolescent.

\section{REFERÊNCIAS}

1. Branski D, Troncone R. Celiac disease: a reappraisal. J Pediatr. 1998;133:181-7.

2. Ciccocioppo R, Sabatino AD, Corazza GR. The immune recognition of gluten in celiac disease. Clin Exp Immunol. 2005;140:408-16.

3. Clemente MG, Musu MP, Frau F, Virgillis S. Guinea pig transglutaminase ELISA: pitfalls in the celiac disease diagnosis [abstract]. J Pediatr Gastroenterol Nutr. 2000;31(Suppl 3):s13 [abstr 40]

4. Dieterich W, Ehnis T, Bauer M, Donner P, Volta U, Riecken EO, Schuppan D. Identification of tissue transglutaminase as the autoantigen of celiac disease. Nat Med. 1997;3:797-801.

5. Dubé C, Rostom A, Sy R, Cranney A, Saloojee N, Garritty C, Sampson M, Zhang L, Yazdi F, Mamaladze V, Pan I, Macneil J, Mack D, Patel D, Moher D. The prevalence of celiac disease in avarage-risk and at-risk Western European populations: a sistematic review. Gastroenterology. 2005;128(Suppl 1):s57-s67.

6. Fasano A, Berti I, Gerarduzzi T, Not T, Colletti RB, Drago S, ElitsurY, Green PH, Guandalini S, Hill ID, Pietzak M, Ventura A, Thorpe M, Kryszak D, Fornalori F, Wassermann SS Murray JA, Horvath K. Prevalence of celiac disease in at-risk and not-at-risk groups in the United States: a large multicenter study. Arch Intern Med. 2003;163:286-92.

7. Feighery C, Conlon N, Jackson J. Adult population screening for coeliac disease: comparasion of tissue-transglutaminasis antibody and anti-endomysial antibody tests. Eur J Gastroenterol Hepatol. 2006;18:1173-5.

8. Ferreira M, Davies SL, Butler M, Scott D, Clark M, Kumar P. Endomysial antibody: is it the best screening test for coeliac disease? Gut. 1992;33:1633-7.

9. Gandolfi L, Bocca AL, Pratesi R. Screening of celiac disease in children attending the outpatient clinic of a university hospital. J Pediatr Gastroenterol Nutr. 2000;31:s212-s3.

10. Gandolfi L, Pratesi R, Cordoba JC, Tauil PL, Gasparin M, Catassi C. Prevalence of celiac disease among blood donors in Brazil. Am J Gastroenterol. 2000;95:689-92.

11. Graig D, Robins GA, Howle PD. Advances in celiac disease. Curr Opin Gastroenterol. 2007;23:142-8.

12. Guandalini S. Celiac disease in the new world. J Pediatr Gastroenterol Nutr. 2000;31:362-4.

13. Hallert C. The epidemiology of celiac disease a continuos enigma. In: Lohiniemi S, Collin P, Mäki M, editors. Changing features of coeliac disease. Tampere: The Finnish Coeliac Society; 1998. p.83-7.

14. Hill ID. What are the sensitivity and specificity of serologic tests for celiac disease? Do sensitivity and specificity vary in different populations? Gastroenterology. 2005; $128: \mathrm{s} 25$-s 32 .
15. Hill ID, Dirks MH, Liptak GS, Colletti RB, Fasano A, Guandalini S, Hoffenberg EJ, Horvath K, Murray JA, Pivor M, Seidman EG; North American Society for Pediatric Gatroenterology, Hepatology and Nutrition. Guideline for the diagnosis and treatment of celiac disease in children: recommendations of the North American Society for Pediatric Gastroenterology, Hepatology and Nutrition. J Pediatr Gastroenterol Nutr. 2005;40:1-19.

16. Hin H, Graham B, Fisher P, Mahy N, Jewell D. Coeliac disease in primary care: case finding study. BMJ. 1999;318:164-7.

17. Kagnoff MF. Overview and pathogenesis of celiac disease. Gastroenterology. 2005;128(Suppl 1):s10-s8.

18. Leffler DA, Kelly CP. Update on the evaluation and diagnosis of celiac disease. Curr Opin Allergy Clin Immunol. 2006;6:191-6.

19. Mäki M. Changing features of coeliac disease. In: Lohiniemi S, Collin P, Mäk $\mathrm{M}$, editors. Changing features of coeliac disease. Tampere: The Finnish Coeliac Society; 1998. p.1-6.

20. Melo SB, Fernandes MI, Peres LC, Troncon LE, Galvão LC. Prevalence and demographic characteristics of celiac disease among blood donors in Ribeirão Preto, State of São Paulo, Brazil. Dig Dis Sci. 2006;51:1020-5.

21. Nemec G, Ventura A, Stefano M, Di Leo GD, Baldas V, Tommasini A, Ferrara F, Taddio A, Cittá A, Sblettero D, Marzari K, Not T. Looking for celiac disease: diagnostic accuracy of two rapid commercial assays. Am J Gastroenterol. 2006;101:1597-600.

22. Norris JM, Barriga K, Hoffenberg EJ, Taki I, Miao D, Haas J, Emery LM, Sokol RJ, Erlich HA, Eisenbarth GS, Rewers M. Risk of celiac disease autoimmunity and timing of gluten introduction in diet of infants at increased risk of disease. JAMA. 2005;293:2343-51

23. Oliveira RP, Sdepanian VL, Baretto JA, Cortez AJ, Carvalho FO, Bordin JO, de Camargo Soares MA, da Silva Patrício FR, Kawakami E, de Morais MB, FagundesNeto U. High prevalence of celiac disease in Brazilian blood donor volunteers based on screening by $\operatorname{IgA}$ antitissue transglutaminase antibody. Eur J Gastroenterol Hepatol. 2007; 19:43-9.

24. Reeves GE, Squance ML, Duggan AE, Murugasu RR, Wilson RJ, Wong RC, Gibson RA, Steele RH, Pollock WK. Diagnostic accuracy of coeliac serological tests: a prospective study. Eur J Gastroenterol Hepatol. 2006;18:493-501.

25. Rodrigues A, Jenkins A. Coeliac disease in children. Current Paediatrics. 2006;16;317-21.

26. Stern $\mathrm{M}$. Working group on serologic screening for celiac disease. Comparative evaluation of serologic tests for celiac disease: a European initiative toward standardization. J Pediatr Gastroenterol Nutr. 2000;31:513-9. 